\title{
Performance Measurement at 2D-CAD Systems
}

\author{
Cabeças, J.Miquel \\ Industrial Production Department, Universidade Nova de Lisboa \\ Quinta da Torre, P-2825 Monte da Caparica, Portugal \\ Tel.351-1-2948542 Fax 351-1-2948546 \\ E-mail:jmm-cabecas@mail.fct.unl.pt
}

\begin{abstract}
This paper addresses performance measurement procedures in operational 2D-CAD systems. The measurement of empowerment levels in CAD systems and the identification of the performance dimensions aligned with the development of the systems was performed, and the results discussed. The conclusions of a test involving the measurement of productivity, efficiency, waste in overproduction and waste in processing are presented.
\end{abstract}

\section{Keywords}

AutoCAD, Performance measurement, Productivity, Efficiency, Waste in production.

\section{INTRODUCTION}

To measure performance in industrial systems, may contribute to the development of the systems (Cabeças, 1994). When performance dimensions are aligned with the development objectives of the systems, the corresponding units of measure may act as a key to reinforce action programs in terms of tactical objectives (Dixon et al.,1990, Pritchard, 1990). The present study was designed (1) to test a methodology to identify those performance dimensions that contribute to the development of operational CAD systems and (2) to test particular performance measures in operational CAD systems as empowerment level, productivity, efficiency, waste in overproduction and waste in processing CAD software. The study involved 5 medium sized engineering and production companies in Portugal (2002.000 employees), with functional structure on the basis of specialised activities such as printed circuit board layout, electrical engineering, steel structures, architectural design and mechanical parts drawings and involving traditional 2-D drawing software on minicomputers. Companies $\mathrm{ABC}$, WUV and $\mathrm{PQR}$ are engineering companies and $\mathrm{XYZ}$ and $\mathrm{JKL}$ are production companies. The study involved 3 professional groups named by CAD operators (C3), design engineers (C2) and functional managers (C1); however, the object of the study was operational $\mathrm{CAD}$ systems (C3), with operators interacting with minicomputers (CPU 386/486 DX2, 25-66 Mhz, 4-8 MB RAM, HD 120-240 MB, Mouse). 


\section{THE EMPOWERMENT LEVELS IN OPERATIONAL CAD SYSTEMS}

The "Questionnaire to Identify Fundamental Activities" was a closed questionnaire with a fixed range of questions and alternative answers, representing in extension the different activities developed by the professional groups $\mathrm{C} 1, \mathrm{C} 2$ and $\mathrm{C} 3$. The activities were grouped in 4 types of functions: technical, social, budget and cost control functions and financial and strategic management functions. It content was based on interviews and direct observations. The questionnaire was used to identify the fundamental activities developed by the professional group C3. The study group included 24 participants. An activity was considered fundamental in the group when developed by more than $80 \%$ of the participants. Table 1 exemplifies the fundamental activities identified in company $\mathrm{ABC}$, a typical company with design engineers-centred responsibilities, where $\mathrm{CAD}$ operators have a low control on internal and external boundaries as well low involvement in the projects.

Table 1 The fundamental activities of group $\mathrm{C} 3$ in company $\mathrm{ABC}$

To calculate weight, quantity and volumes.

To consult national technical standards and internal company standards.

To consult technical catalogues of components and equipment (dimensional aspects).

To maintain daily technical contact with operators from the same department.

To execute drawings in $\mathrm{CAD}$ stations.

$\mathrm{CAD}$ operators receive specific guide lines from design engineers concerning the work to develop, with autonomy to technical conception of the products.

Based on the activities developed by CAD operators in the different companies, it was possible to determinate the corresponding empowerment levels (Table 2). An 100\% empowerment level means that all the operators develop all the activities on the empowerment criteria.

Table 2 The empowerment levels of professional group C3

\begin{tabular}{|c|c|c|c|c|c|}
\hline Empowerment criterion & $\begin{array}{l}A B C \\
\text { scores }\end{array}$ & $\begin{array}{l}X Y Z \\
\text { scores }\end{array}$ & $\begin{array}{l}\text { WUV } \\
\text { scores }\end{array}$ & $\begin{array}{l}J K L \\
\text { scores }\end{array}$ & $\begin{array}{l}\text { Max. } \\
\text { scores }\end{array}$ \\
\hline Production capability & 282 & 534 & 191 & 600 & 700 \\
\hline Capacity to consult technical documentation & 382 & 700 & 80 & 100 & 700 \\
\hline Cross-functions & 172 & 267 & 60 & 80 & 300 \\
\hline Control on the external boundary & 109 & 300 & 20 & 100 & 300 \\
\hline Control in the internal boundary & 273 & 334 & 280 & 400 & 500 \\
\hline Autonomy & 190 & 300 & 40 & 300 & 400 \\
\hline Involvement & 72 & 133 & 40 & 300 & 400 \\
\hline Control monitor and schedule of work flow & 54 & 233 & 120 & 100 & 300 \\
\hline Empowerment level & $43 \%$ & $78 \%$ & $23 \%$ & $\mathbf{5 5 \%}$ & 3.600 \\
\hline
\end{tabular}

We found different empowerment levels in the companies (from $23 \%$ to $78 \%$ ). Social variables as personal selection and performance evaluation as well budget control, cost control and strategic variables are not controlled by CAD operators. Particularly in companies $\mathrm{ABC}$ and WUV the involvement in the projects was very low as a result of poor knowledge on clients specifications and on the different groups involved in the same project. Also in both companies, it was found low scores on autonomy as a result of high dependence on design engineers. In company JKL we found high scores in production capability as a result of technical capacity to perform calculations, materials lists, specifications and reports. Also in 
company XYZ we found high control on the external boundary, as a result of high interaction with products suppliers, production plants and subcontractors. In company WUV we found low scores in the capacity to consult technical documentation as a result of an incidence on company standards involving dimensional aspects of the product.

\section{THE SELECTION OF PERFORMANCE DIMENSIONS}

It was developed the "Questionnaire to Evaluate Performance Dimensions", in order to identify those dimensions related to the development of system C3. It was a closed questionnaire, using the Likert's rating method (5-point scale). The study group included 17 design engineers and functional managers; the object of the questions was system $\mathrm{C} 3$. The questionnaire covered 41 performance subdimentions (Cabeças, 1992), grouped in 9 dimensions: flexibility, dependability, functional waste, productivity, quality, innovation, efficiency, effectiveness and quality of work life. The following question was used to evaluate functional waste in products and information flow:

"Waste time spent by CAD operators on obtaining and transmitting information, documentation or drawings to CAD colleagues or design engineers, in the actual department or between company departments.
(A) Actual situation
High waste
$123+5$ Low waste
(D) Desired and possible situation
High waste
$123+5$ Low waste"

Three types of objectives resulted from the questionnaire:

1. Relevant objectives: with high desired and possible scores (D).

2. Maintenance objectives: relevant objectives with high actual scores (A).

3. Priority objectives: with high difference between desired and actual scores (D-A).

Table 3 illustrates the priority and relevant objectives. They represent shared targets in the companies to which the actions, performance measures and goals must be oriented in order to develop operational CAD systems.

Table 3 Priority and relevant objectives identified in systems C3

Code Priority and relevant objectives

DE.6 Waste reduction in human motions: to reduce waste time spent by CAD operators on elementary motions and displacements in the work place due to work methods and work place layout.

IN.4 Innovation in the functional structure: to innovate in the type of interaction between CAD operators and other departments in the company.

DE.3 Waste reduction in products and information flow: to reduce waste time spent by $\mathrm{CAD}$ operators on obtaining and transmitting information, documentation or drawings to $\mathrm{CAD}$ colleagues or design engineers, in the actual department or between departments.

DE.7 Waste reduction in delays: to reduce waste in delays due to difficulties in synchronising the project activities in different departments (project planning).

QU.3 Increase input quality: increase information and specifications quality from internal suppliers.

DC. 1 On time delivery to internal clients.

FL.2 Increase flexibility in products quality: increase the ability to produce drawings with different levels of quality. 
Table 4 Average and standard deviation values for the priority and relevant objectives (Range 1-5, $\mathrm{N}=17$ )

\begin{tabular}{lllll}
\hline Code & $\begin{array}{l}\text { Average } \\
(D)\end{array}$ & $\begin{array}{l}\text { Average } \\
(D-A)\end{array}$ & $\begin{array}{l}\text { Std. dev. } \\
(D)\end{array}$ & $\begin{array}{l}\text { Std. dev. } \\
(D-A)\end{array}$ \\
\hline DE.6 & 4.4 & 2.1 & 0.5 & 1.1 \\
IN.4 & 4.3 & 1.9 & 0.7 & 1.0 \\
DE.3 & 4.5 & 1.8 & 0.5 & 0.9 \\
DE.7 & 4.7 & 1.7 & 0.5 & 1.4 \\
QU.3 & 4.6 & 1.6 & 0.5 & 0.7 \\
DC.1 & 4.7 & 1.5 & 0.5 & 1.0 \\
FL.2 & 4.6 & 1.5 & 0.5 & 0.9 \\
\hline
\end{tabular}

To reduce waste in human movements and in products/information flow, and innovation in the functional structure of the companies represent priority development objectives. However, to reduce waste in delays, to increase input quality, on time delivery and flexibility in products quality are simultaneously relevant objectives (high desired score).

Waste in delays, and waste in human motions show the highest dispersion in the answers. These results transmit the perspective of design engineers and functional managers on the development of systems C3. A questionnaire involving a study group of $14 \mathrm{CAD}$ operators identified different priorities in the development of the systems. The main origins of functional waste identified in systems $\mathrm{C} 3$ are represented on Table 5.

Table 5 The main origins of functional waste in systems $\mathrm{C} 3$

\begin{tabular}{ll} 
Origins of functional waste & Total Scores \\
\hline Modifications introduced by external clients in products specifications & 10 \\
Incomplete work specifications & 5 \\
Interruptions in the work been processed by CAD operators & 4 \\
Computer very "slow" & 4 \\
Lack of software training & 3 \\
\hline
\end{tabular}

These results show different perspectives of operational CAD systems. Frequent modifications and interruptions during processing, and work specifications with deficient information was the main origins of waste identified by CAD operators.

\section{PRODUCTIVITY IN OPERATIONAL CAD SYSTEMS}

The impact of CAD software in the productivity of engineering systems has been referred to by the literature (Majcrzak, 1987, Chorafas, 1987). Productivity in CAD systems may be evaluated by the ratio between system output and time or labour involved in obtaining the output (labour productivity) (Sink, 1985). In this study, productivity was measured in 4 systems: company ABC (Architecture department), company ABC (Structures department) and company WUV. The ratio between the number of drawings produced and the time involved in processing was the unit to measure productivity. The number of drawings produced were normalised to $\mathrm{A} 0$ format $(1 \mathrm{~A} 4=1 / 16 \mathrm{~A} 0,1 \mathrm{~A} 3=1 / 8 \mathrm{~A} 0,1 \mathrm{~A} 2=1 / 4 \mathrm{~A} 0$ and $1 \mathrm{~A} 1=1 / 2 \mathrm{~A} 0$ ). In company $\mathrm{ABC}$ (Architecture department) were observed 6 different orders (Table 6 ) and in Structures department 11 orders, for a 6 weeks period. In WUV it was measured the productivity of a 5 operators group during 5 working days. 
Table 6 The productivity in company ABC (Architecture)

\begin{tabular}{lrllllllll}
\hline Weeks & & 1 & 2 & 3 & 4 & 5 & 6 & Total \\
Number of drawings & (Drw.) & 11.60 & 14.60 & 3.20 & 5.00 & 12.60 & 5.00 & 52.00 \\
Working hours & (Hours) & 93.00 & 150.00 & 107.50 & 63.50 & 88.00 & 124.00 & 626.00 \\
Productivity (Draw./ Hour) & $\mathbf{0 . 1 2 4}$ & $\mathbf{0 . 0 9 7}$ & $\mathbf{0 . 0 3 0}$ & $\mathbf{0 . 0 7 9}$ & $\mathbf{0 . 1 4 3}$ & $\mathbf{0 . 0 4 0}$ & $\mathbf{0 . 0 8 3}$ \\
\hline
\end{tabular}

The average productivity values of $0.083,0.192$ and 0.146 drawings/hour were calculated in the 3 systems. However It was found a low correlation between the number of drawings produced and the hours involved in processing. The correlation factors were respectively $0.86,0.46$ and 0.27 and consequently a productivity increase may not be related to a reduction in cycle time or to an increase in production capacity. In these particular cases, the unit of measure selected was not adequate to evaluate the improvements in the systems. In the base of this fact is a high diversity of products developed in CAD systems: drawings, specifications, calculation sheets, materials lists, sketches, modifications, final drawings and preliminary drawings.

\section{EFFICIENCY IN OPERATIONAL CAD SYSTEMS}

Efficiency is associated to the ratio between resources expected to be consumed and resources actually consumed. It was measured weekly, at company $\mathrm{ABC}$ - Electricity and Architecture departments - using the variable time, through the following expression:

- $\mathrm{T}$ : Period considered to measure efficiency (1 week)

- HO: Time estimate to the order been processed

- HR: Time actually consumed in the order during period T

- $\mathrm{R}$ : Percentage of the order processed during period $\mathrm{T}$

$$
\text { Efficiency }=H O * R / H R
$$

The same production order may involve different drawings, developed by different operators. In the systems analysed the time estimates were aggregated by order. Table 7 exemplifies the calculation of the time expected to be weekly consumed in 6 different orders, and Table 8 the actual values of efficiency.

Table 7 The weekly time estimate in the Architecture department when performing orders A to $\mathrm{Q}$

Percentage of the order processed each week

\begin{tabular}{|c|c|c|c|c|c|c|c|}
\hline $\begin{array}{l}\text { Order } \\
\text { code }\end{array}$ & $\begin{array}{c}\text { Orders time estimate } \\
\text { (hours) }\end{array}$ & $\begin{array}{c}\text { Week l } \\
(\%)\end{array}$ & $\begin{array}{c}\text { Week } 2 \\
(\%)\end{array}$ & $\begin{array}{c}\text { Week } 3 \\
(\%)\end{array}$ & $\begin{array}{l}\text { Week } 4 \\
(\%)\end{array}$ & $\begin{array}{c}\text { Week } 5 \\
(\%)\end{array}$ & $\begin{array}{c}\text { Week } 6 \\
(\%)\end{array}$ \\
\hline A & 96.0 & 60 & 0 & & 40 & & \\
\hline B & 37.5 & 100 & & & & & \\
\hline $\mathrm{C}$ & 525.0 & 5 & 15 & & & 15 & 5 \\
\hline D & 85.0 & & 15 & 85 & & & \\
\hline E & 400.0 & & 5 & 5 & 15 & & \\
\hline \multirow[t]{2}{*}{$\mathrm{F}$} & 96.0 & & & & & 40 & 40 \\
\hline & Time estimate (hrs.) & 121.4 & 111.5 & 92.3 & 98.4 & 117.2 & 64.7 \\
\hline
\end{tabular}


Table 8 The efficiency in company ABC - Architecture department, when processing orders

\begin{tabular}{rllllllll}
\multicolumn{1}{c}{ A to $\mathrm{F}$} \\
\hline Week & 1 & 2 & 3 & + & 5 & 6 & Total \\
\hline Weekly time estimate (hours) & 121.4 & 111.5 & 92.3 & 98.4 & 117.2 & 64.7 & 605.5 \\
Time actually spent (hours) & 93.0 & 150.0 & 107.5 & 63.5 & 88.0 & 124.0 & 626.0 \\
Efficiency (\%) & $\mathbf{1 3 1}$ & $\mathbf{7 4}$ & $\mathbf{8 6}$ & $\mathbf{1 5 5}$ & $\mathbf{1 3 3}$ & $\mathbf{5 2}$ & $\mathbf{9 7 \%}$
\end{tabular}

Average efficiency values of $97 \%$ and $94 \%$ were calculated at Architecture and Structures department. We found two main difficulties on applying this procedure to measure efficiency: (1) some of the orders processed in CAD departments are not specified with a time estimate and (2) it was not always obvious to quantify the percentage of the order that was weekly processed.

\section{WASTE IN OVERPRODUCTION IN OPERATIONAL CAD SYSTEMS}

In CAD systems overproduction (Shingo, 1989) was associated to the volume of modifications introduced at the work in process. Main origins of modifications were found: (1) modifications in clients specifications, (2) desynchronised information flow between different departments, (3) to initiate the processing in a preliminary stage without the knowledge of the whole information and (4) the development of a best solution.

It was measured at company $\mathrm{ABC}$ (Architecture department) and at company WUV. In the first case for 6 weeks and concerning 17 particular orders (named A to Q) and in the second company for 15 days and concerning the work developed by a group of $5 \mathrm{CAD}$ operators. It was a subjective assessment, based on the information reported by $\mathrm{CAD}$ operators in a registration form. It was asked the operators to quantify the time involved in modifications, and identify the corresponding origins in a predetermined set of options. The results are summarised on Tables 9 and 10 to company $\mathrm{ABC}$ and on Table 11 to company WUV.

Table 9 The waste in overproduction in company ABC, Architecture department, when processing orders $A$ to $F$.

\begin{tabular}{l|lllllll}
\hline Week & 1 & 2 & 3 & 4 & 5 & 6 & Total \\
\hline $\begin{array}{l}\text { Time involved in modifications } \\
\text { (hours) }\end{array}$ & 4.0 & 3.0 & 14.5 & 17.5 & 3.0 & 8.0 & 50.0 \\
Production time (hours) & 93.0 & 150.0 & 107.5 & 63.5 & 88.0 & 124.0 & 626.0 \\
Waste in overproduction (\%) & $\mathbf{4 . 3}$ & $\mathbf{2 . 0}$ & $\mathbf{1 3 . 5}$ & $\mathbf{2 7 . 6}$ & $\mathbf{3 . 4}$ & $\mathbf{6 . 5}$ & $\mathbf{7 . 9 \%}$ \\
\hline
\end{tabular}

Table 10 The waste in overproduction in company ABC, Electricity department, when processing orders $\mathrm{G}$ to $\mathrm{Q}$.

\begin{tabular}{llllllll}
\hline week & 1 & 2 & 3 & + & 5 & Total \\
\hline Time involved in modification (hours) & 8.0 & 38.0 & 9.0 & 65.0 & 26.0 & 146.0 \\
Production time (hours) & 76.5 & 106.0 & 105.0 & 108.0 & 61.0 & 456.5 \\
Waste in overproduction (\%) & $\mathbf{1 0 . 4}$ & $\mathbf{3 5 . 9}$ & $\mathbf{8 . 6}$ & $\mathbf{6 0 . 2}$ & $\mathbf{4 2 . 6}$ & $\mathbf{3 2 . 0 \%}$ \\
\hline
\end{tabular}


Table 11 The waste in overproduction of a 5 operators group for 15 working days, at company WUV

\begin{tabular}{llllllll}
\hline CAD operators code & $D .1$ & $D .2$ & $D .3$ & $D .4$ & $D .5$ & Total \\
\hline $\begin{array}{l}\text { Time involved in modifications } \\
\text { (minutes) }\end{array}$ & 0 & 1920 & 150 & 0 & 3875 & 5945 \\
$\begin{array}{l}\text { Production time (hours) } \\
\text { Waste in overproduction (\%) }\end{array}$ & 118.0 & $\mathbf{0}$ & $\mathbf{2 8 . 4}$ & $\mathbf{2 . 2}$ & $\mathbf{0}$ & $\mathbf{5 8 . 2}$ & $\mathbf{1 7 . 5 \%}$ \\
\hline
\end{tabular}

Three main difficulties were found in quantifying waste in overproduction: (1) the concept of modification was not always obviously, particularly the distinction between modification and rectification, (2) the time involved in a particular modification was not always easily quantifiable and (3) we may expect errors related to human factors as accuracy in time measurement, data not registered and data incorrectly registered.

\section{WASTE IN PROCESSING IN OPERATIONAL CAD SYSTEMS}

Non-value added time on processing $\mathrm{CAD}$ software is a measure of waste in processing (Shingo, 1989). Different origins of non-value added time may be found in CAD systems: (1) specific CAD and DOS instructions that do not add value to the product as Purge, Regen, Save, Open, Zoom Extended, Backup 's, Format and Copy (2) time spent on "organising" the hard disk, (3) time spent on creating plot files and picking up drawings in printers, (4) hardware characteristics not adequate to the specifications of CAD software, slowing the speed of the operations (5) monitors not adequate to the effective use of CAD software, (6) frequent interruptions during processing and (7) unavailable information needed to an effective processing of the order. At company JKL, the quantification was focused on the following 5 main causes: (1)Time needed to establish telecommunications with European drawings databases. (2) Excess time during processing due to incomplete information transmitted by internal clients and customers. (3) Waste time spent in the rectification of errors occurred during CAD operations. (4) Waste time due to difficulties in interpersonal communication (colleagues not available). (5) Other causes.

The time spent by a group of 5 operators during 10 days, on these particular non-value added activities, was registered on a special form, and the results summarised on Table 12.

Table 12 Non-value added time spent by a group of $5 \mathrm{CAD}$ operators when processing in company JKL

\begin{tabular}{llll}
\hline Days & $\begin{array}{l}\text { Processing time } \\
\text { Minutes }\end{array}$ & $\begin{array}{l}\text { Waste time } \\
\text { Minutes }\end{array}$ & $\begin{array}{l}\text { Waste time } \\
\text { Percentage }\end{array}$ \\
\hline 1 & 2113 & 365 & 17 \\
2 & 1975 & 625 & 32 \\
3 & 2060 & 705 & 34 \\
4 & 1541 & 430 & 28 \\
5 & 2095 & 530 & 25 \\
6 & 1625 & 80 & 5 \\
7 & 1340 & 165 & 12 \\
8 & 1610 & 340 & 21 \\
9 & 1383 & 45 & 3 \\
10 & 1375 & 240 & 17 \\
Total & $\mathbf{1 7 1 1 7}$ & $\mathbf{3 5 2 5}$ & $\mathbf{2 1} \%$ \\
\hline
\end{tabular}




\section{CONCLUSIONS}

We have found in companies $\mathrm{ABC}$ and WUV, low empowerment levels and high functional dependence of $\mathrm{CAD}$ operators on design engineers. This dependence on design engineers may be ineffective and result in high levels of waste in overproduction. To measure productivity in operational CAD systems with a high variety of activities, based on the number of drawings produced may not be adequate. To measure efficiency in operational CAD systems may be adequate if the orders have a time estimate and if we can measure with accuracy the proportion processed during the measurement period. High levels of modifications, interruptions and rectification, the technical characteristics of hardware and software, lack of training, and an ineffective interaction with internal clients, customers and colleagues may lead to high levels of waste in processing in operational CAD systems. In the 5 companies observed, the performance of operational CAD systems concerning productivity, efficiency, and waste in production depends on the balance in a group of factors, particularly (1) CAD software characteristics (2) Interpersonal and interdepartmental information flow: network software utilisation (3) Hardware characteristics: processing speed, monitor dimensions, centralised software and working files (4) Printing: printers location and printing effectiveness; bureaucratic procedures (5) Empowerment levels of CAD operators and (6) Cultural aspects of the companies.

\section{REFERENCES}

Dixon, Robb J., Alfred J. Nanni, Jr., and Thomas E. Vollmann (1990) The New Performance Challenge : Measuring Operations for World-Class Competition. Dow Jones-Irwin, Illinois.

Pritchard, Robert D. (1990) Measuring and Improving Organisational Productivity: a Practical Guide. Praeger Publishers, New York.

Sink, D. Scott. (1985) Productivity Management : Planning, Measurement and Evaluation, Control and Improvement. John Wiley \& Sons, New York.

Shingo, Shingeo (1989) A Study of the Toyota Production System From an Industrial Engineering Viewpoint. Productivity Press, Cambridge MA.

Majchrzak, Ann et al. (1987) Human Aspects of Computer-Aided Design. Taylor and Francis Philadelphia, PA.

Chorafas, Dimitris N. (1987) Engineering Productivity Through CAD/CAM. Butterworths London.

Cabeças, J.Miquel (1992) Sensores, Métrica e Niveis Organizacionais: Conceitos Fundamentais para Planear a Avaliação do Desempenho em Sistemas de Produção. Revista da Ordem dos Engenheiros - INGENIUM, Nº 63, pp. 40-49, Lisboa.

Cabeças, J.Miquel (1994) Como Selecionar Medidas de Desempenho em Sistemas Industriais?. Revista Portuguesa de Gestão, NNII, 1994, pp. 75-81, Lisboa.

\section{BIOGRAPHY}

Mechanical Engineering, Ph.D. candidate, teaching Ergonomics and Work Organization at Industrial Production Department, Faculty of Ciences and Technology, Universidade Nova de Lisboa. Research interests: ergonomics, work organization and performance measurement. 